\title{
Patent Ductus Arteriosus and the Effects of Its Late Closure in Preterm Infants with Severe Bronchopulmonary Dysplasia
}

\author{
Sophia M. Ansems ${ }^{a, b}$ Haresh Kirpalani ${ }^{b}$ Laura Mercer-Rosac ${ }^{c}$ Yan Wang ${ }^{c}$ Rachel K. Hopper ${ }^{c}$ \\ María V. Fraga ${ }^{b}$ Erik A. Jensen ${ }^{b}$ \\ a University of Groningen, Groningen, The Netherlands; ${ }^{\text {b}}$ Division of Neonatology, Department of Pediatrics, \\ The Children's Hospital of Philadelphia, University of Pennsylvania School of Medicine, Philadelphia, PA, USA; \\ 'Division of Cardiology, Department of Pediatrics, The Children's Hospital of Philadelphia, University of \\ Pennsylvania School of Medicine, Philadelphia, PA, USA
}

\section{Keywords}

Premature infant · Bronchopulmonary dysplasia · Persistent patent ductus arteriosus - Echocardiography

\begin{abstract}
Background: The natural history and optimal management of a patent ductus arteriosus (PDA) among infants with established severe bronchopulmonary dysplasia (sBPD) remains uncertain. Objectives: To describe the characteristics of PDA present at $\geq 36$ weeks' postmenstrual age (PMA) and the effects of late surgical PDA closure in a referral cohort of very preterm infants with sBPD. Study Design: This retrospective cohort study was performed in a tertiary neonatal intensive care unit. Study infants were born at $<32$ weeks' gestation between 2010 and 2016, diagnosed with sBPD, and had an echocardiographic PDA at $\geq 36$ weeks' PMA. We reviewed echocardiograms performed closest to 3 time points ( $\geq 36$ weeks' PMA, hospital discharge, and 1 year of age) and assessed clinical outcomes among infants with versus without late PDA treatment. Results: Among 329 infants with sBPD, 59 had a PDA at $\geq 36$ weeks' PMA. Most PDAs were small $(n=33)$ and shunted left to right $(n=53)$. The PDA closed spontaneously prior to discharge in 5 of 21 infants
\end{abstract}

\begin{tabular}{ll}
\hline KARGER & ( 2019 The Author(s) \\
& Published by S. Karger AG, Basel Oparger \\
E-Mail karger@karger.com & This article is licensed under the Creative Commons Attribution- \\
www.karger.com/neo & $\begin{array}{l}\text { NonCommercial-NoDerivatives 4.0 International License (CC BY- } \\
\text { NC-ND) (http://www.karger.com/Services/OpenAccessLicense). } \\
\text { Usage and distribution for commercial purposes as well as any dis- } \\
\text { tribution of modified material requires written permission. }\end{array}$
\end{tabular}

who did not undergo surgical closure and decreased in size in 3. The PDA spontaneously closed by 1 year of age in 6 out of 12 infants with an open duct at discharge. PDA surgery ( $n=23$ ) at $\geq 36$ weeks' PMA was not associated with increased risk for the composite outcome of tracheostomy, systemic vasodilator at discharge, or death after adjusting for potential confounders (OR 3.2, 95\% Cl 0.81-13.0). Conclusions: The majority of conservatively treated late PDAs closed spontaneously or decreased in size. PDA surgery was not associated with severe adverse clinical outcomes.

(c) 2019 The Author(s)
Published by S. Karger AG, Basel

\section{Introduction}

Bronchopulmonary dysplasia (BPD) is the most common chronic complication of preterm birth [1]. It is associated with multiple adverse childhood outcomes including neurodevelopmental impairment, growth failure, long-term deficits in cardiopulmonary health, and late death [2]. The presence of a patent ductus arteriosus (PDA) has been associated with the development of BPD [3-6]. It is unknown whether this association is causal, as 
early medical or surgical PDA closure does not reduce BPD risk $[7,8]$. Owing to the lack of apparent benefit of early PDA treatment, many clinicians now avoid closing the PDA during the neonatal hospitalization [9-11]. However, as spontaneous ductal closure can take considerable time in very preterm infants, the PDA in some babies persists beyond 36 weeks' postmenstrual age (PMA). Possibly, continued exposure to a PDA in infants who develop severe BPD (sBPD) may delay lung disease recovery and exacerbate BPD-associated pulmonary hypertension $(\mathrm{PHT})$. Prior reports describing the natural history and cardiorespiratory effects of a prolonged PDA provide limited information about infants with sBPD [12-15].

This study's primary objective was to describe the epidemiology of a persistent PDA beyond 36 weeks' PMA in a tertiary, referral-based cohort of infants with sBPD. We paid particular attention to ductal size and shunt direction. This analysis describes rates of spontaneous and surgical PDA closure, and the association between late PDA surgery and adverse in-hospital outcomes.

\section{Materials and Methods}

\section{Setting and Subjects}

Our institution is a tertiary referral center that primarily cares for outborn infants transferred from neonatal intensive care units (NICUs) in the surrounding region. For this retrospective cohort study, we queried our prospectively maintained registry to identify all infants born $<32$ weeks' gestation who developed sBPD (according to the $2001 \mathrm{NIH}$ consensus definition [16]) and were transferred to our institution between October 2010 and July 2016. Infants born with major congenital anomalies and those without echocardiographic data were excluded. The Institutional Review Board at the Children's Hospital of Philadelphia approved this study.

\section{Data Collection}

Demographic and clinical data were abstracted from our institutional medical record. Reports from all echocardiograms (echo's) performed at our institution were reviewed for the presence of a PDA at $\geq 36$ weeks' PMA. For the infants without a documented PDA after $\geq 36$ weeks' PMA, data on the closure method (spontaneous/medical/surgical) were collected. A senior pediatric echocardiographer, who was blinded to all other clinical information, reassessed all echos with a reported presence of a PDA. For infants with a persistent PDA at $\geq 36$ weeks' PMA, the echocardiographic duct characteristics (size and shunt direction) were reevaluated in up to 3 echos performed at the following time points: (1) the first echo performed at $\geq 36$ weeks' PMA for infants without subsequent surgical PDA treatment, or the last echo performed prior to surgical closure; (2) closest to NICU discharge; and (3) 1 year chronological age.

PDA Size and Treatment

In our study, a small PDA had a diameter $<50 \%$ of the proximal pulmonary artery (PA) branch measured just after branching from the main PA. A moderate PDA had a diameter $50-100 \%$ of the proximal PA branch, and a large PDA had a diameter larger than the PA branch. "PDA surgery" or "surgical PDA closure" refers to an open surgical ligation procedure or interventional cardiac catheterization using an occlusive closure device.

\section{Outcomes}

The primary study outcome was a composite of tracheostomy, treatment with a systemic pulmonary vasodilator at NICU discharge, or death prior to discharge. The individual components were also analyzed as secondary outcomes. The risks for these outcomes were compared between infants with and without evidence of a PDA at $\geq 36$ weeks' PMA and among those who did versus did not undergo surgical treatment for a PDA beyond $\geq 36$ weeks' PMA.

Rates of postoperative clinical decompensation were assessed among infants with PDA surgery at $\geq 36$ weeks' PMA. This outcome was defined as the presence of $\geq 1$ of the following criteria: (1) $>20 \%$ increase in fraction of inspired oxygen 48 h post-surgery; (2) initiation of pulmonary vasodilator therapy within 2 weeks postoperatively; (3) pharmacological hypotension treatment for $\geq 24$ h during the first postoperative week; and (4) evaluation for sepsis (blood culture and/or new antibiotics prescribed for $\geq 48 \mathrm{~h}$ ) during the first postoperative week.

\section{Statistical Analysis}

Standard descriptive statistics were used to compare the demographic and clinical characteristics between the different subgroups. Non-normally distributed data are reported as median and interquartile range (IQR). Study outcomes were evaluated with the $\chi^{2}$ or Fisher's exact test as appropriate. Multivariable logistic regression, adjusting for gestational age, birth weight, sex, and mechanical ventilation at 36 weeks' PMA, was used to assess the independent association between surgical PDA closure, PDA shunt direction/size, and the study outcomes. The set significance level was $p \leq 0.05$. Data were processed with Microsoft Excel Office Professional Plus 2013 and analyzed using IBM SPSS version 24.0.

\section{Results}

\section{Study Cohort}

We identified 329 infants born $<32$ weeks' gestation diagnosed with sBPD (Fig. 1). The demographic characteristics were similar between infants with and without a PDA at $\geq 36$ weeks' PMA (Table 1). Median birth weights were modestly lower among infants with than infants without PDA surgery at $\geq 36$ weeks' PMA (Table 1 ). Table 2 shows demographics and outcomes for infants with PDA closure at $<36$ weeks' PMA.

\section{Echo Evaluation at $\geq 36$ Weeks' PMA}

The PDA size, shunt direction, and subsequent PDA course from 36 weeks' PMA through approximately 1 year of age are summarized in Figure 1. Of 329 infants included in the study, 59 (18\%) were diagnosed with a PDA at $\geq 36$ weeks' PMA by echocardiographic evalua- 


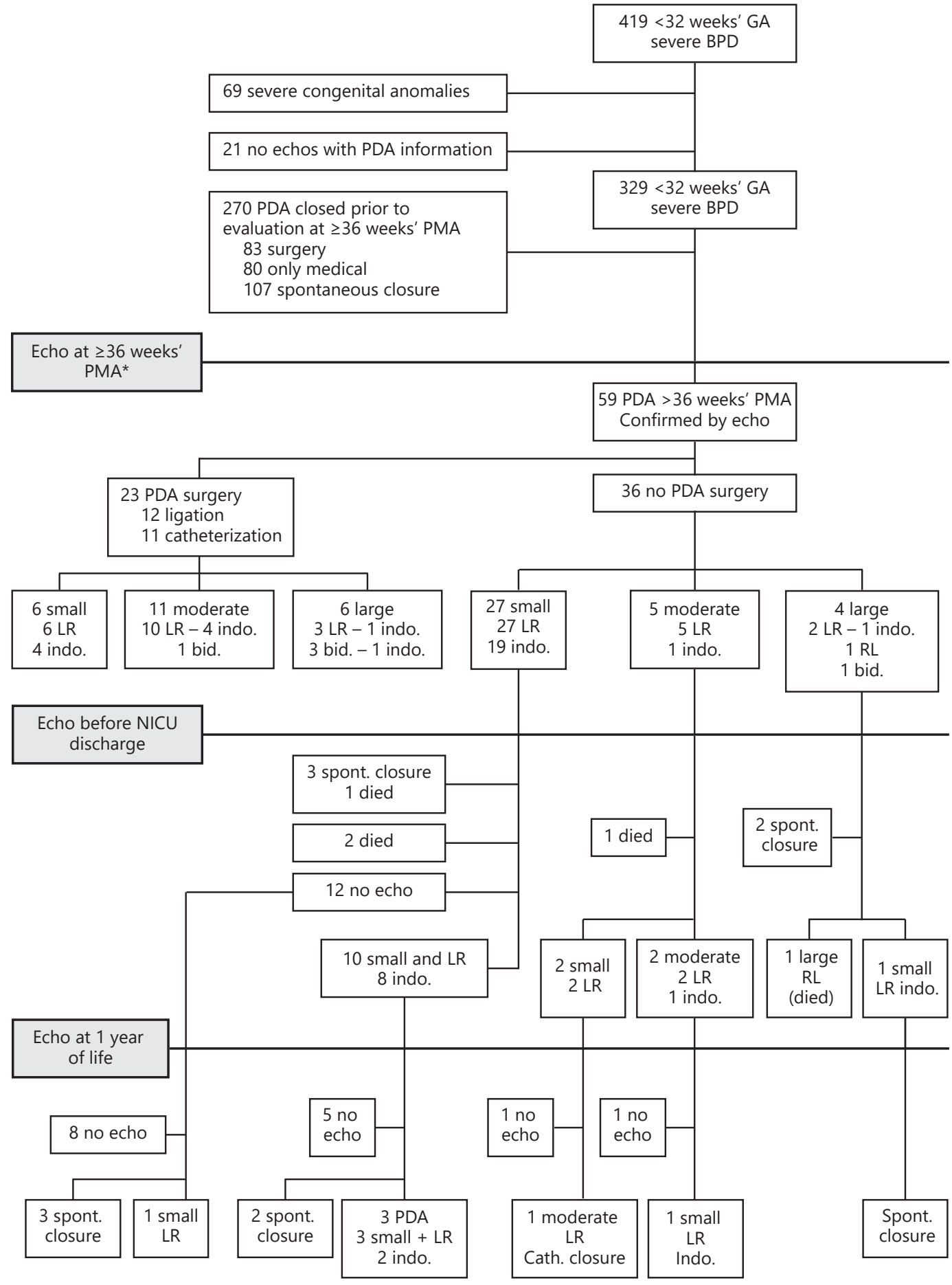

Fig. 1. Patient flow chart describing PDA occurrence in the study cohort. bid., bidirectional; BPD, bronchopulmonary dysplasia; cath., catheterization; echo, echocardiogram; GA, gestational age; indo., indomethacin (history of indomethacin failure before 36

weeks' postmenstrual age, PMA); NICU, neonatal intensive care unit; PDA, patent ductus arteriosus; spont., spontaneous; *, performed at a median PMA of 39.6 weeks (IQR 37.4-42.3 weeks). 
Table 1. Demographics of infants with and without PDA at $\geq 36$ weeks' PMA and infants with and without PDA surgery at $\geq 36$ weeks' PMA

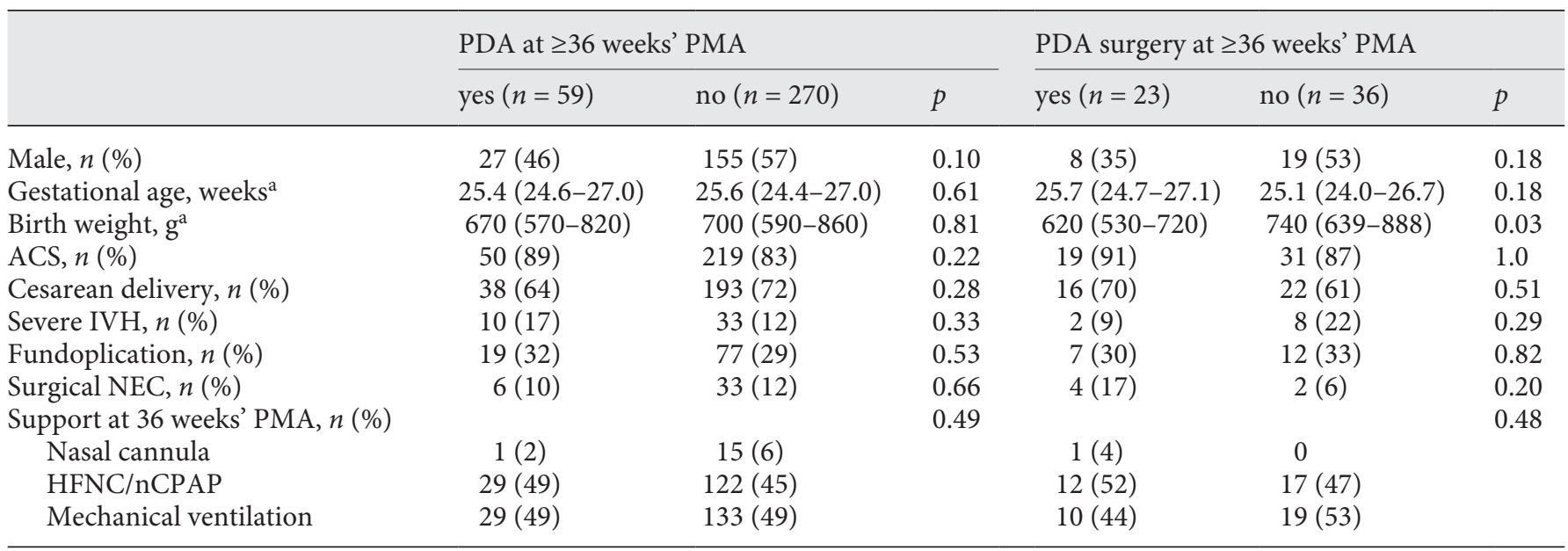

ACS, antenatal corticosteroids; HFNC, high-flow nasal cannula; IVH, intraventricular hemorrhage; NEC, necrotizing enterocolitis; nCPAP, nasal continuous positive airway pressure; PDA, patent ductus arteriosus; PMA, postmenstrual age. ${ }^{a}$ Variables expressed as median (interquartile range).

Table 2. Demographic characteristics and outcomes for infants with PDA closure before 36 weeks' PMA

\begin{tabular}{|c|c|c|c|c|}
\hline & $\begin{array}{l}\text { Surgical } \\
(n=83)\end{array}$ & $\begin{array}{l}\text { Medical } \\
(n=80)\end{array}$ & $\begin{array}{l}\text { Spontaneous } \\
(n=107)\end{array}$ & $p$ \\
\hline Male, $n(\%)$ & $44(53)$ & $45(56)$ & $65(62)$ & 0.56 \\
\hline Birth weight, $\mathrm{g}^{\mathrm{a}}$ & $640(565-740)$ & $707(606-884)$ & $745(610-933)$ & $<0.01$ \\
\hline $\mathrm{ACS}, n(\%)$ & $64(77)$ & $65(82)$ & $90(84)$ & 0.47 \\
\hline Cesarean delivery, $n(\%)$ & $51(61)$ & $58(73)$ & $84(79)$ & 0.04 \\
\hline Fundoplication, $n(\%)$ & $21(25)$ & $20(25)$ & $36(34)$ & 0.32 \\
\hline Surgical NEC, $n(\%)$ & $9(11)$ & $12(15)$ & $12(11)$ & 0.66 \\
\hline Support at 36 weeks' PMA, $n(\%)$ & & & & $<0.01$ \\
\hline Nasal cannula & $2(2)$ & $4(5)$ & $9(8)$ & \\
\hline $\mathrm{HFNC/nCPAP}$ & $26(31)$ & $48(60)$ & $48(45)$ & \\
\hline Mechanical ventilation & $55(66)$ & $28(35)$ & $50(47)$ & \\
\hline Trach. at discharge among survivors, $n(\%)^{\mathrm{b}}$ & $16(22)$ & $14(19)$ & $26(27)$ & 0.47 \\
\hline
\end{tabular}

ACS, antenatal corticosteroids; HFNC, high-flow nasal cannula; IVH, intraventricular hemorrhage; med., medication; NEC, necrotizing enterocolitis; nCPAP, nasal continuous positive airway pressure; PDA, patent ductus arteriosus; PHT, pulmonary hypertension; PMA, postmenstrual age; syst., systemic; trach., tracheostomy. ${ }^{\text {a }}$ Variables expressed as median (interquartile range). ${ }^{\mathrm{b}}$ Survivors among infants with surgical closure, $n=72$; survivors among infants with medical closure; $n=63$, survivors among infants with spontaneous closure; $n=96$.

Patent Ductus Arteriosus in Severe Bronchopulmonary Dysplasia
Neonatology 2019;116:236-243

DOI: $10.1159 / 000500269$ 
Table 3. Primary outcome and its components for infants with and without PDA at $\geq 36$ weeks' PMA

\begin{tabular}{|c|c|c|c|c|}
\hline & $\begin{array}{l}\text { PDA } \geq 36 \text { wk PMA } \\
(n=59)\end{array}$ & $\begin{array}{l}\text { No PDA } \geq 36 \text { wk PMA } \\
(n=270)\end{array}$ & $\begin{array}{l}\text { Unadjusted } \\
p\end{array}$ & $\begin{array}{l}\text { Adjusted OR } \\
(95 \% \mathrm{CI})\end{array}$ \\
\hline Trach./syst. PHT med./death, $n(\%)$ & $29(49 \%)$ & $97(36 \%)$ & 0.06 & $1.8(1.0-3.3)$ \\
\hline Syst. PHT med. at discharge among survivors, $n(\%)^{\mathrm{a}}$ & $9(19 \%)$ & $30(12 \%)$ & 0.24 & $1.6(0.69-3.8)$ \\
\hline Trach. at discharge among survivors, $n(\%)^{\mathrm{a}}$ & $12(25 \%)$ & $56(23 \%)$ & 0.79 & $1.2(0.58-2.6)$ \\
\hline Mortality & $11(19 \%)$ & $29(11 \%)$ & 0.09 & $2.0(0.90-4.4)$ \\
\hline
\end{tabular}

med., medication; PDA, patent ductus arteriosus; PHT, pulmonary hypertension; PMA, postmenstrual age; syst., systemic; trach., tracheostomy. ' Survivors among infants with PDA at $\geq 36$ weeks' PMA, $n=48$; survivors among infants without PDA at $\geq 36$ weeks' PMA, $n=241$. $^{\mathrm{b}}$ Adjusted for birth weight, gestational age, gender and mechanical ventilation at 36 weeks' PMA.

Table 4. Primary outcome and its components for infants with and without PDA surgery

\begin{tabular}{|c|c|c|c|c|}
\hline & $\begin{array}{l}\text { PDA surgery } \\
(n=23)\end{array}$ & $\begin{array}{l}\text { No PDA surgery } \\
(n=36)\end{array}$ & $\begin{array}{l}\text { Unadjusted } \\
p\end{array}$ & $\begin{array}{l}\text { Adjusted OR }{ }^{\mathrm{b}} \\
(95 \% \mathrm{CI})\end{array}$ \\
\hline Trach. syst. PHT med./death, $n(\%)$ & $14(61 \%)$ & $15(42 \%)$ & 0.15 & $3.2(0.81-13.0)$ \\
\hline Trach. at discharge among survivors, $n(\%)^{\mathrm{a}}$ & $3(18 \%)$ & $9(29 \%)$ & 0.50 & $0.67(0.11-4.0)$ \\
\hline Mortality, $n(\%)$ & $6(26 \%)$ & $5(14 \%)$ & 0.31 & $3.7(0.72-18.7)$ \\
\hline
\end{tabular}

med., medication; PDA, patent ductus arteriosus; PHT, pulmonary hypertension; PMA, postmenstrual age; syst., systemic; trach., tracheostomy. a Survivors among infants with PDA surgery, $n=17$; survivors among infants without PDA surgery, $n=31 .{ }^{\mathrm{b}}$ Adjusted for birth weight, gestational age, gender, mechanical ventilation at 36 weeks' PMA and PDA size.

tion. We found documentation of prior indomethacin therapy failure in 31/59 infants. By the time of NICU discharge, 23/59 infants (39\%) had undergone PDA surgery. Most of those infants (13/23) had a moderate-large and left-to-right shunting PDA.

Only 6 infants with echocardiographic evidence of a PDA at $\geq 36$ weeks' PMA had bidirectional $(n=5)$ or rightto-left $(n=1)$ ductal shunting on the initial study echo (Fig. 1). Four of these 6 underwent surgical closure, 1 through open surgical ligation and 3 with catheterization. The infant treated with surgical ligation began to deteriorate 9 days postoperatively, and care was withdrawn 8 days later following a prolonged period of cardiorespiratory deterioration. Of the 3 infants with bidirectional PDAs treated by catheterization, 2 were discharged home on sildenafil.

\section{Echo Evaluation prior to NICU Discharge in \\ Non-Surgically Treated Infants}

Among 36 infants with a conservatively treated PDA at $\geq 36$ weeks' PMA, 21 had a second echo performed prior to NICU discharge (median PMA 44.0 weeks, IQR 41.1-50.9) (Fig. 1). The 12 remaining surviving infants without a second echo all previously had a small and leftto-right-shunting PDA. No PDAs with available echo data increased in size after 36 weeks' PMA. The bidirectional and right-to-left shunting PDAs both spontaneously closed before NICU discharge (confirmed by echo).

Five out of 36 non-surgically treated infants died between 36 weeks' PMA and NICU discharge. Four out of these 5 infants had a small or moderate and left-to-right shunting PDA. The other infant had a large and left-toright shunting PDA. This PDA changed to a right-to-left shunting duct on subsequent echos and following a prolonged period of hypoxemic failure, care was withdrawn at 38 weeks' PMA.

\section{Echo Evaluation at 1 Year of Age}

Among 28 infants with an open PDA at NICU discharge, 12 underwent echocardiography near 1 year of age (median age of 10.3 months; IQR 7.9-14.5 months). Six infants showed spontaneous PDA closure, all within 9 months' post-discharge. All infants with an open PDA at this time point had a small and left-to-right shunting duct. One patient underwent closure by catheterization at 
6 months of age (PMA 53 weeks). This baby was tracheostomy dependent and transferred to a chronic care facility from the NICU. The last echo prior to closure showed a moderate and left-to-right shunting PDA but with evidence of right ventricular hypertrophy.

\section{Study Outcomes}

Rates of the primary composite and individual secondary outcomes were similar among the infants with compared to without a PDA at $\geq 36$ weeks' PMA (Table 3). Multivariable analysis showed that the presence of a PDA was associated with a marginally significant increase in the odds of developing the primary study outcome (Table 3 ). The adjusted odds of the individual secondary outcomes were similar between the groups (Table 3 ).

There was no difference in the risk for the primary outcome comparing infants with versus without surgical PDA closure (Table 4). Treatment with a systemic pulmonary vasodilator at discharge was more common among infants with than without surgical PDA closure. This association was not statistically significant after adjusting for earlier treatment with a systemic pulmonary vasodilator and other confounding variables (OR 5.3, 95\% CI 0.40-71.3). There was no significant association between PDA size or shunting direction and the risks for the primary or secondary outcomes (data not shown).

Eleven out of 23 PDA surgery infants experienced postoperative clinical deterioration. There was no statistically significant association between PDA size (adjusted OR 3.0, 95\% CI 0.30-29) or shunt direction (adjusted OR $0.63,95 \%$ CI $0.05-8.3$ ) and the risk for postoperative deterioration in the univariable or multivariable analyses.

\section{Discussion/Conclusion}

Limited published data describe echocardiographic findings and natural history of late PDA among infants with sBPD. In this large, referral cohort of sBPD infants, we found that $18 \%$ had echocardiographic evidence of a PDA at $\geq 36$ weeks' PMA. This rate is higher than previously reported in preterm infants. A retrospective evaluation of 391 very low birth weight $(<1,500 \mathrm{~g})$ infants born between 2004 and 2005 reported the presence of a persistent PDA at approximately 38 weeks' PMA in 5\% [13]. Notably, the timing of echocardiographic evaluation at $\geq 36$ weeks and indomethacin exposure rates among the infants with a prolonged PDA were similar between our and this prior study [13]. The higher incidence of a prolonged PDA in our patients may be explained by the

Patent Ductus Arteriosus in Severe

Bronchopulmonary Dysplasia greater severity of lung disease in our population, or by change in practice towards less surgical PDA treatment [9]. Half of the evaluated infants with an open ductus at NICU discharge in our cohort demonstrated spontaneous closure by 1 year chronological age. In contrast, 2 studies reported spontaneous postdischarge PDA closure rates ranging between 81 and $86 \%$ in very low birth weight infants without sBPD $[12,13]$. However, both studies used clinical examination to assess PDA closure in some infants, potentially overestimating spontaneous closure rates $[12,13]$. Notably, most PDAs in both studies [12, 13], and ours, were small. The clinical dilemma for most neonatologists is not the management of a small PDA, but whether it is safe to leave a moderate-to-large PDA untreated [17]. Our data showed that most moderate-tolarge PDAs closed spontaneously or decreased in size over time. However, our small sample size mandates that these findings be interpreted with caution.

Although the optimal care of a PDA remains controversial, there is likely a trend toward conservative treatment. A large cohort study found that rates of conservative PDA management increased between 2006 and 2012, while pharmacotherapy and/or surgical ligation decreased [9]. An American cohort study reported that between 2006 and 2015 rates of medical and surgical PDA treatment decreased, while the median age at PDA ligation increased [11]. If this reflects modern practice, more infants with established BPD may present with a persistent PDA. The risk to benefit balance of closing the ductus in these infants is unclear. Prolonged exposure to a left to right shunt may lead to lung disease progression and development of PHT. However, surgical PDA closure has well-established risks $[18,19]$. Moreover, when PHT is already present, ductal closure may remove a potential "safety valve" needed to off-load the right ventricle in times of high pulmonary vascular resistance $[8,18-21]$.

Most studies in preterm infants have focused on early rather than late ( $\geq 36$ weeks' PMA) PDA surgery $[19,21]$. The aggregate finding was a lack of improvement in neonatal and neurodevelopmental outcomes after PDA surgery [22]. The sole statistically significant association we found was increased odds of discharge on pulmonary vasodilator therapy among infants with late PDA surgery. Since the finding was no longer statistically significant after multivariable analysis, the observed difference in outcome is likely attributable to treatment bias rather than the surgical procedure itself. As most studies examining the effects of PDA closure are observational in nature, confounding by indication is common in this field of research [23]. Large randomized clinical trials are re- 
quired to accurately characterize the risks and benefits of late ductal closure.

This study was conducted in a tertiary referral hospital and most likely represents the care provided for this patient category. We acknowledge the limitations imposed by a retrospective review of the medical record. Importantly, we can only draw inferences about association, because of potential bias from unmeasured confounding that influenced treatment decisions and the risks for the study outcome. Unfortunately, there were only a modest number of babies with an echo available at all 3 study time points. Consequently, we were not able to describe the complete PDA course in all infants. However, the assessment of all echocardiograms by an experienced echocardiographer blinded to other clinical outcomes and not the use of echo reports is a key study strength. Nonetheless, the classification of PDA size and shunting direction is subject to interrater reliability [24].

In conclusion, we described that most late PDAs in this sBPD cohort were small in size and shunted from left-toright. Most conservatively treated late PDAs closed spontaneously or decreased in size. To guide neonatologists making decisions regarding the treatment of late PDA in infants with sBPD, future research should explore the short- and long-term outcomes after late surgical PDA closure and the long-term consequences of prolonged ductal patency in this patient population.

\section{Statement of Ethics}

Subjects (their parents or guardians) have given their written informed consent. The study protocol has been approved by the Institutional Review Board at the Children's Hospital of Philadelphia.

\section{Disclosure Statement}

The authors have no conflict of interest to declare.

\section{Funding Sources}

The authors have no source of funding to declare.

\section{Author Contributions}

Sophia M. Ansems' authorship contribution consisted of conceptualization, methodology, investigation, supervision, data curation, and formal analysis of this study. Erik A. Jensen's authorship contribution consisted of conceptualization, methodology, investigation, supervision, data curation, and formal analysis of this study. Haresh Kirpalani's authorship contribution consisted of conceptualization, methodology, and supervision of this study. Laura Mercer-Rosa's authorship contribution consisted of conceptualization, methodology, and investigation of this study. Yan Wang's authorship contribution consisted of investigation of this study. Rachel K. Hopper's authorship contribution consisted of methodology and investigation of this study. Maria V. Fraga's authorship contribution consisted of conceptualization and methodology of this study.

\section{References}

1 Stoll BJ, Hansen NI, Bell EF, Walsh MC, Carlo WA, Shankaran S, et al.; Eunice Kennedy Shriver National Institute of Child Health and Human Development Neonatal Research Network. Trends in Care Practices, Morbidity, and Mortality of Extremely Preterm Neonates, 1993-2012. JAMA. 2015 Sep;314(10): 1039-51.

2 Jensen EA, Schmidt B. Epidemiology of bronchopulmonary dysplasia. Birth Defects Res A Clin Mol Teratol. 2014 Mar;100(3): 145-57.

3 Rojas MA, Gonzalez A, Bancalari E, Claure N, Poole C, Silva-Neto G. Changing trends in the epidemiology and pathogenesis of neonatal chronic lung disease. J Pediatr. 1995 Apr; 126(4):605-10.

4 Palta M, Gabbert D, Weinstein MR, Peters ME. Multivariate assessment of traditional risk factors for chronic lung disease in very low birth weight neonates. The Newborn Lung Project. J Pediatr. 1991 Aug;119(2):285-92.

5 Trzaski JM, Hagadorn JI, Hussain N, Schwenn J, Wittenzellner C. Predictors of successful discontinuation of supplemental oxygen in very low-birth-weight infants with bronchopulmonary dysplasia approaching neonatal intensive care unit discharge. Am J Perinatol. 2012 Feb;29(2):7986.

6 Marshall DD, Kotelchuck M, Young TE, Bose CL, Kruyer L, O'Shea TM; North Carolina Neonatologists Association. Risk factors for chronic lung disease in the surfactant era: a North Carolina population-based study of very low birth weight infants. Pediatrics. 1999 Dec;104(6):1345-50.

7 Schmidt B, Roberts RS, Fanaroff A, Davis P, Kirpalani HM, Nwaesei C, et al.; TIPP Investigators. Indomethacin prophylaxis, patent ductus arteriosus, and the risk of bronchopulmonary dysplasia: further analyses from the Trial of Indomethacin Prophylaxis in Preterms (TIPP). J Pediatr. 2006 Jun;148(6):7304.

8 Clyman R, Cassady G, Kirklin JK, Collins M, Philips JB 3rd. The role of patent ductus arteriosus ligation in bronchopulmonary dysplasia: reexamining a randomized controlled trial. J Pediatr. 2009 Jun;154(6):873-6.
9 Lokku A, Mirea L, Lee SK, Shah PS; Canadian Neonatal Network. Trends and Outcomes of Patent Ductus Arteriosus Treatment in Very Preterm Infants in Canada. Am J Perinatol. 2017 Apr;34(5):441-50.

10 Ngo S, Profit J, Gould JB, Lee HC. Trends in Patent Ductus Arteriosus Diagnosis and Management for Very Low Birth Weight Infants. Pediatrics. 2017 Apr;139(4):e20162390.

11 Bixler GM, Powers GC, Clark RH, Walker MW, Tolia VN. Changes in the Diagnosis and Management of Patent Ductus Arteriosus from 2006 to 2015 in United States Neonatal Intensive Care Units. J Pediatr. 2017 Oct;189:105-12.

12 Weber SC, Weiss K, Bührer C, Hansmann G, Koehne P, Sallmon H. Natural History of Patent Ductus Arteriosus in Very Low Birth Weight Infants after Discharge. J Pediatr. 2015 Nov; 167(5):1149-51.

13 Herrman K, Bose C, Lewis K, Laughon M. Spontaneous closure of the patent ductus arteriosus in very low birth weight infants following discharge from the neonatal unit. Arch Dis Child Fetal Neonatal Ed. 2009 Jan; 94(1):F48-50. 
14 Jhaveri N, Moon-Grady A, Clyman RI. Early surgical ligation versus a conservative approach for management of patent ductus arteriosus that fails to close after indomethacin treatment. J Pediatr 2010 Sep;157(3):381-7, 387.e1.

15 Vanhaesebrouck S, Zonnenberg I, Vandervoort P, Bruneel E, Van Hoestenberghe MR, Theyskens $\mathrm{C}$. Conservative treatment for patent ductus arteriosus in the preterm. Arch Dis Child Fetal Neonatal Ed. 2007 Jul;92(4):F244-7.

16 Jobe AH, Bancalari E. Bronchopulmonary dysplasia. Am J Respir Crit Care Med. 2001 Jun;163(7):1723-9.

17 Reese J, Laughon MM. The Patent Ductus Arteriosus Problem: Infants Who Still Need Treatment. J Pediatr. 2015 Nov;167(5):954-6.
18 Clyman RI, Couto J, Murphy GM. Patent ductus arteriosus: are current neonatal treatment options better or worse than no treatment at all? Semin Perinatol. 2012 Apr;36(2):123-9.

19 Moin F, Kennedy KA, Moya FR. Risk factors predicting vasopressor use after patent ductus arteriosus ligation. Am J Perinatol. 2003 Aug; 20(6):313-20.

20 Madan JC, Kendrick D, Hagadorn JI, Frantz ID 3rd; National Institute of Child Health and Human Development Neonatal Research Network. Patent ductus arteriosus therapy: impact on neonatal and 18-month outcome. Pediatrics. 2009 Feb;123(2):674-81.

21 Cassady G, Crouse DT, Kirklin JW, Strange MJ, Joiner CH, Godoy G, et al. A randomized, controlled trial of very early prophylactic ligation of the ductus arteriosus in babies who weighed $1000 \mathrm{~g}$ or less at birth. N Engl J Med. 1989 Jun;320(23):1511-6.
22 El-Khuffash A, Weisz DE, McNamara PJ. Reflections of the changes in patent ductus arteriosus management during the last 10 years. Arch Dis Child Fetal Neonatal Ed. 2016 Sep; 101(5):F474-8.

23 Weisz DE, More K, McNamara PJ, Shah PS PDA ligation and health outcomes: a metaanalysis. Pediatrics. 2014 Apr;133(4):e102446.

24 Schwarz CE, Preusche A, Baden W, Poets CF, Franz AR. Repeatability of echocardiographic parameters to evaluate the hemodynamic relevance of patent ductus arteriosus in preterm infants: a prospective observational study. BMC Pediatr 2016 Jan; $16: 18$. 